\title{
Framework for intake simulation of functional ingredients
}

\author{
Janneke Kloosterman *, Martine I Bakker, Nynke de Jong and Marga C Ocké \\ National Institute for Public Health and the Environment, PO Box 1, 3720, BA Bilthoven, The Netherlands
}

Submitted 11 September 2006: Accepted 28 March 2007: First published online 26 July 2007

\begin{abstract}
Objective: To create a general framework for the simulation of intakes from mandatory or voluntary fortification, which will make outcomes of simulation studies more comparable and give insight on uncertainties.

Design: A general framework was developed based on methods used in already published case studies of mandatory fortification. The framework was extended to be suitable for the simulation of voluntary fortification. Case studies of folic acid fortification were used to illustrate the general framework.

Results: The developed framework consists of six steps. First, the definition of the fortification strategy (step 1), followed by the identification of potential carrier products (step 2), and the definition of fortification levels or ranges (step 3). Thereafter, virtual food/supplement composition data are created (step 4) and food/supplement consumption data are required (step 5). Finally, the intake of the functional ingredient from functional foods, other foods and dietary supplements is calculated during the simulation resulting in total habitual intake distributions (step 6).

Conclusions: Simulation of both mandatory and voluntary folic acid fortification in The Netherlands showed that the general framework is applicable. Also with incomplete data or data from different sources, the (habitual) intake distributions can be estimated using assumptions, statistical procedures or probabilistic modelling approaches. It is important that the simulation procedure is described well, so that an insight on uncertainties and knowledge gaps to be filled is given.
\end{abstract}

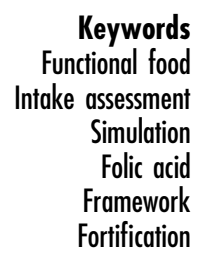

Originally, the purpose of adding micronutrients to foods and using supplements was to prevent deficiency diseases. Nowadays, there is an additional health focus: the prevention of chronic diseases ${ }^{1}$. Also, it is claimed that the addition of other bio-active ingredients to foods and supplements, like phytosterols, will help to improve health. As a consequence, consumers are currently exposed to higher amounts and different ratios of micronutrients and to a range of new ingredients compared to earlier times. Because of international changes in and harmonisation of fortification policies and the ongoing introduction of new functional foods, the exposure to these ingredients will remain subject to change.

Authorities can influence the intake of functional ingredients from fortified foods by regulating either mandatory or voluntary fortification programmes. In mandatory fortification, all selected products are required to be fortified with certain amounts of a functional ingredient. In voluntary fortification, manufacturers are permitted to fortify (selected) products, but this is not compulsory. For a governmental policy on fortification, it is important to have insights in the current population intake distributions to identify potential nutritional problems and to compare current intakes with any expected intake changes. Calculation of the expected future population intake distribution after fortification is useful for several reasons; to gain insights into the impact of potential decisions of policy-makers and to determine which policy will result in the desired or most optimal effect. At this moment, some specific case studies have been published in which the intake of fortified foods or functional ingredients is simulated ${ }^{2-10}$. These case studies had different goals, but all of them simulated mandatory fortification. Although these studies had more or less similar methodologies, a uniform framework to simulate the intake of functional ingredients, from fortified foods, other foods and dietary supplements, was not used.

A simulation framework to assess intake is required to perform uniform and systematic comparisons of different exposure scenarios and eventually benefit-risk evaluations. Such a uniform framework will provide a systematic insight on the effect of different food policies and may help policy-makers to choose the most optimal scenario based on quantitative results. In addition, using a uniform framework will make possible the comparison between 
different policies, studies and countries. The use of a uniform framework will also give insight in uncertainties in the simulation, for instance, caused by lack of data or assumptions made. In this paper, we describe such a framework that will be applicable for many functional ingredients. Of course, because of the enormous variability in functional ingredients, at some points different strategies may be followed, examples of which will be presented. Our framework is illustrated by simulation of both mandatory and voluntary folic acid fortification.

\section{General methodology}

Our general framework for the simulation of the intake of functional ingredients at a population level consists of six steps (Fig. 1). We will first outline each step and then illustrate the process with simulations of folic acid fortification.

\section{Fortification strategy (step 1)}

Authorities may influence the intake of functional ingredients by the population through various strategies: (1) promote supplementation, (2) mandatory fortification or (3) voluntary fortification. The fortification strategy chosen depends on, among others, the current intake distribution of the population, the proportion of subjects with an inadequate and/or excessive intake and the desired intake distribution. In addition, factors such as costs and enforcement will also influence the choice of a final strategy.

\section{Carrier products: type of foods and/or supplements (step 2)}

Next, carrier products need to be selected. In principle, both foods and supplements can be used as carrier products. In the case of mandatory fortification, the target population is a large part of the total population. Therefore, the food(s) chosen should be consumed frequently and by a large proportion of the population. For this reason, supplements are considered not suitable ${ }^{11,12}$, while staple foods appear to be a good choice.

For voluntary fortification, both foods and supplements can be carrier products. In theory, all foods that technically can be fortified may be a carrier product. However, authorities may select specific products that may or may not be fortified. An example of the latter are alcoholic beverages. Factors like consumer awareness, price and health focus will influence the degree of intake.

For both mandatory and voluntary fortification approaches, international experiences ${ }^{8,9}$, scientific studies with fortified foods ${ }^{13}$, but also existing/requested (inter)national permissions ${ }^{5,14}$ can be used to select the carrier products. Besides, current consumption distributions of foods can help to choose carrier products that are for example consumed mainly by the target population ${ }^{6}$.

\section{Level of fortification (step 3)}

Next, fortification levels have to be chosen. These levels may be adopted from international fortification experiences or from levels used in scientific studies. If the aim is to increase the intake in a (sub)population to reach a certain level, the known difference between current intake and desired intake may be used to calculate potential fortification levels ${ }^{8}$. Moreover, (inter)national regulations about the minimum level of the functional ingredient to carry a claim on the product ${ }^{7}$, but also (inter)national set maximum levels for fortification ${ }^{15,16}$ or existing/requested (inter)national permissions ${ }^{5,14}$ may be useful. If previous experience is not available, the choice of fortification levels has to be based on the best educated guess. In practice, this will mean that with 'trialand-error', levels are chosen to get close to the aim.

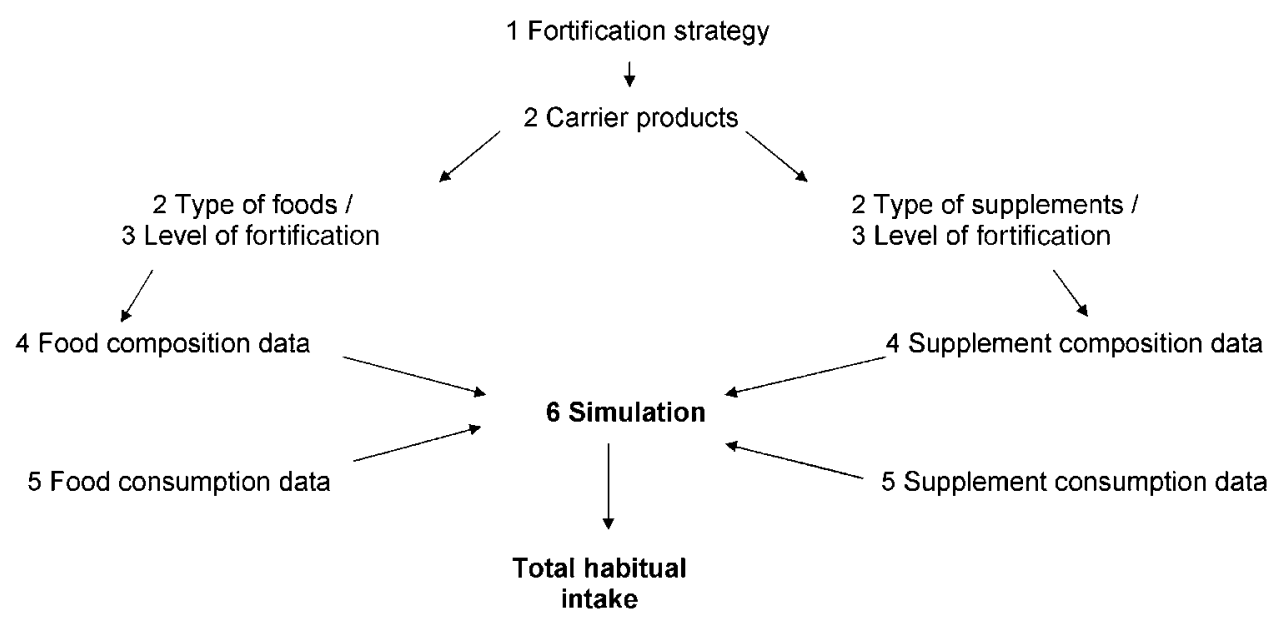

Fig. 1 Systematic framework for the simulation of intake of functional ingredients 
Important factors herein are consumption pattern, current intake distribution of the functional ingredient, and if available, the margin between the recommended intake and the tolerable upper intake level (UL).

\section{Food and supplement composition data (step 4)}

In order to simulate the intake of functional ingredients, the current composition of the carrier products should be virtually replaced by the composition after fortification. In many countries, national food composition tables are available ${ }^{17,18}$. However, some specific compounds are not (completely) covered by these tables. The missing composition might be estimated using data from foreign countries, from additional analytical analyses, recipe calculations or from information obtained from experts or manufacturers. Sometimes the functional ingredient is not part of the background (i.e. unfortified) diet. In that case, the functional ingredient should be added to the food composition table to create the virtual food composition.

Supplement composition data are difficult to obtain. Nevertheless, such data are important for the calculation of the total intake of functional ingredients from different sources ${ }^{19}$.

\section{Food and supplement consumption data (step 5)}

Because adverse health effects are often the result of a chronic inadequate or excessive intake, long-term exposure is usually of interest. Consequently, habitual (also referred to as usual) intakes should be estimated. Several methodologies are available to assess food and supplement consumption ${ }^{20}$. Long-term methods can be used to assess habitual intake of foods or food groups and when the amount consumed is known, also the habitual intake of nutrients can be used ${ }^{20}$. Short-term methods will give information about actual intakes and can only be used to estimate habitual nutrient intake by statistical correction for day-to-day (i.e. within-person) variation ${ }^{21-25}$. This day-to-day variation depends on the nutrient, the population under study and seasonal variation in consumption $^{26}$. Consumption data of representative samples of the whole population should be available to extrapolate the results to a population level. However, sample sizes used in national food consumption surveys are often too small to estimate habitual intake of (a) products consumed by only a small subpopulation or (b) products consumed infrequently ${ }^{27}$.

\section{Simulation of total babitual intake (step 6)}

The next step is simulation of fortification with the functional ingredient. One should remember that functional ingredients can be either the natural substances or their chemical equivalents, which may have different characteristics, e.g. difference in bioavailability. Therefore, ingredient-specific adaptations of the procedure may be necessary.
In the optimal situation, consumption of food and supplements is measured at the same time, in the same representative population (large enough sample size), and with similar methods. In that case, the simulated total habitual intake of the functional ingredient can be estimated by adding up the habitual intake from different sources per individual. However, this 'straightforward' approach is often not possible due to lacking data and a small sample size ${ }^{11,28}$. In those cases, total habitual intake needs to be estimated based on data measured at different periods, in different study populations, with different methods, or even with some specific data lacking. In the literature, several approaches have been suggested to deal with this less optimal situation ${ }^{19,29}$. Probabilistic modelling can be used to estimate the total intake of a functional ingredient by combining the intake originating from longterm and short-term methods or from different study populations. Also, if some of the data are unknown, probabilistic modelling can be used to calculate the total habitual intake by imputation of the missing data ${ }^{30-32}$.

\section{Simulation of mandatory fortification}

For the simulation of mandatory fortification, all counterparts of the carrier product(s) will be replaced by virtually fortified products. The virtual food composition data will be combined with the consumption data to calculate the intake of the functional ingredient (i.e. sum of consumed amount $\times$ functional ingredient concentration).

\section{Simulation of voluntary fortification}

In the simulation of voluntary fortification, virtual new food composition data cannot be created as 'straightforward' as described for mandatory fortification, as there are more uncertainties. First of all, it is unknown what the manufacturers will do, e.g. what proportion of carrier product(s) will be fortified and at what fortification level? In voluntary fortification, the fortification levels are more likely to vary compared to mandatory fortification. Secondly, little is known about consumers' behaviour when there is a choice between fortified and unfortified products. The proportion of consumers can be estimated from available (inter)national consumption data, market shares or empirically when no data are available. Thirdly, there are practical problems to perform the simulation because the required data need to be very detailed which is often not the case. Brand-specific consumption data may not be available, and sample sizes in surveys are usually too small to get a representative sample of the consumers of specific or infrequently consumed products. Besides, when short-term methods are used, many participants may not consume these voluntary fortified products at all during the survey, but may not represent true non-consumers ${ }^{27}$.

The simulations can be performed by making assumptions for the aspects described above and can 


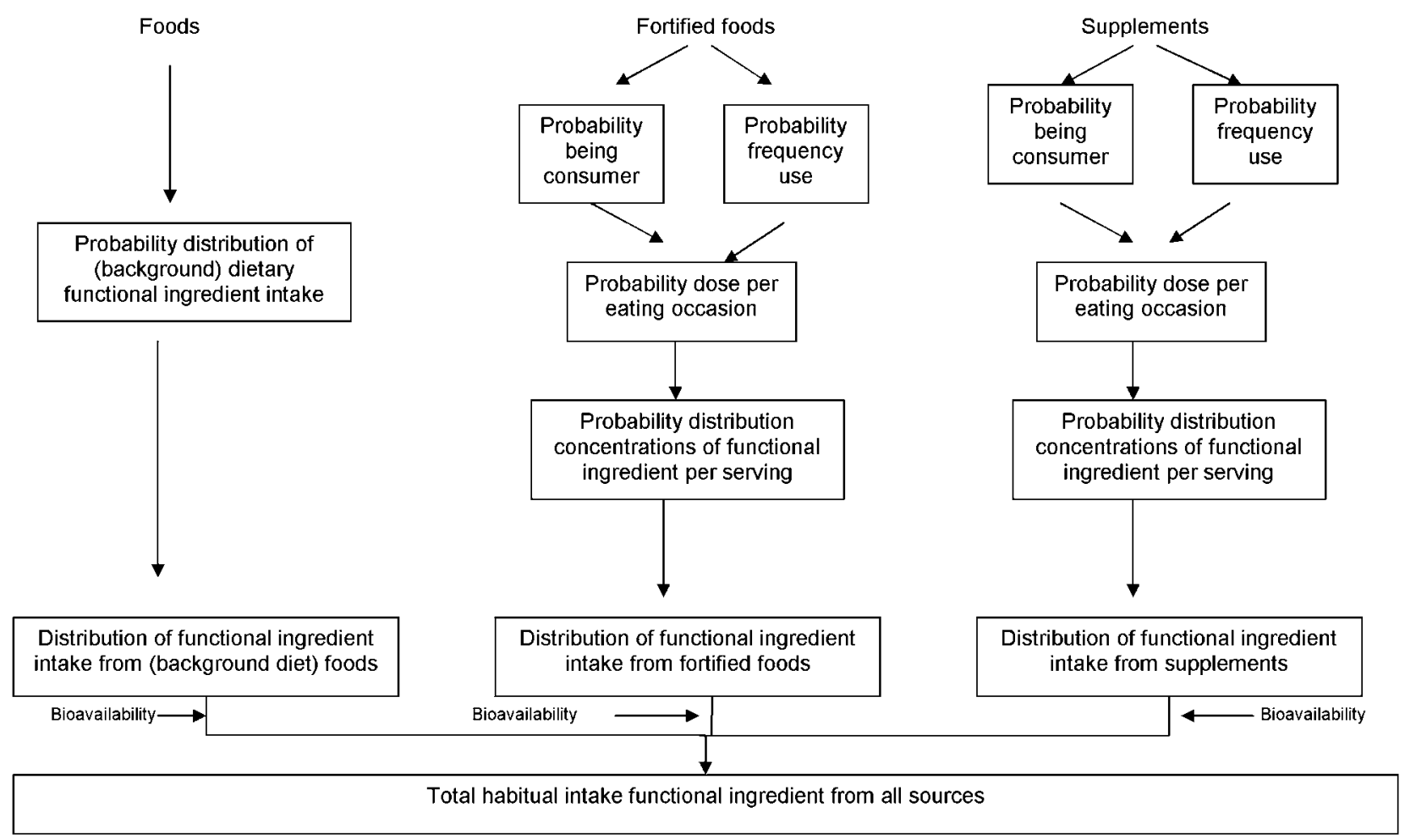

Fig. 2 Model for probabilistic modelling of a nutrient adapted from Gibney and McCarthy ${ }^{30}$ and Gibney and Van der Voet ${ }^{31}$

calculate the intake distributions given those assumptions. A probabilistic approach, as described by Gibney and McCarthy ${ }^{30}$ and Gibney and Van der Voet ${ }^{31}$, in which the probabilities of being a consumer, the frequency of use and the dose per eating occasion are estimated, may be useful (Fig. 2) ${ }^{30,31}$. With this methodology, it is possible to combine the various assumptions based on their probability and quantify the uncertainty caused by these assumptions. When several levels of fortification are assumed, probabilistic modelling can help to predict the probability distribution of the concentration of the functional ingredients in foods.

\section{Case study: folic acid fortification}

The framework (Fig. 1) described above is illustrated by the simulation of both mandatory and voluntary folic acid fortification in The Netherlands. Folic acid from supplements was ignored in this illustration. Data used in both simulations are described first. Next, the case-specific steps for mandatory and voluntary fortification are presented and several, case-specific, assumptions are discussed. Finally, in the results section, examples of output of the various fortification scenarios are presented.

\section{Data}

The most recent Dutch food consumption data for the total population were used, which is the Dutch National
Food Consumption Survey-3 (DNFCS-3) (step 5) ${ }^{33}$. Respondents (6250 persons aged 1-97 years from 2564 households) recorded their food intake over two consecutive days. The data were collected in 1997/1998 and were equally distributed over seasons and the days of the week.

Nutrient intakes were calculated by combining individual consumption data with the Dutch food composition table 2001 (step 4$)^{17,34}$. Since the bioavailability of folic acid is assumed to be higher than that of natural folate, the concentration units were converted into folateequivalents ${ }^{35}$. Whereas $1 \mu \mathrm{g}$ folic acid in foods equals $1.7 \mu \mathrm{g}$ folate-equivalents, $1 \mu \mathrm{g}$ natural folate is equal to $1 \mu \mathrm{g}$ folate-equivalents ${ }^{36,37}$. The amounts of functional ingredient added to the products were assumed to be present in the end products.

Because long-term intake was of interest, statistical correction for day-to-day variation was applied using the ISU-method (IML/C-SIDE-software) ${ }^{38}$ (step 6) ${ }^{21,22}$. Intake distributions were calculated for various age-gender groups. Unless otherwise stated, calculations were performed with Statistical Analysis Software (SAS version 9.1; SAS Institute).

\section{Mandatory folic acid fortification}

Simulation of mandatory folic acid fortification (step 1) is illustrated with two staple foods as carrier products (step 2). Bread was selected because of the international experiences with mandatory flour fortification ${ }^{39-41}$. The 
chosen fixed fortification levels, i.e. 70, 140, 280 and $420 \mu \mathrm{g}$ per $100 \mathrm{~g}$ bread, were based on the level of $140 \mu \mathrm{g}$ per $100 \mathrm{~g}$ flour advised in the USA (step 3$)^{40}$. Half and multiples of this level were selected to get an insight on the effect of different fortification levels. To study the effect of mandatory fortification of different products, a second staple food, i.e. (butter)milk, was selected (step 2). Based on experience in scientific studies, four fixed fortification levels were chosen; 20, 40, 80 and $160 \mu \mathrm{g}$ per $100 \mathrm{ml}$ (step 3) ${ }^{42}$.

In the food composition table, each level of folic acid was added to all (whole) bread or (butter)milk products except for raw milk (step 4). Total dietary folateequivalent intake was calculated by summation of the total intake of natural folate and folic acid, expressed as folate-equivalents. It was assumed that observed non-consumption on both reported days was true nonconsumption.

\section{Voluntary folic acid fortification}

Recently several food products (specific brands) got exemption for voluntary folic acid fortification in The Netherlands (www.row.minvws.nl). Of these products, we chose margarine as an example in the simulation of voluntary fortification (steps 1-2). The fortification level of $500 \mu \mathrm{g}$ per $100 \mathrm{~g}$ stated in the application of the manufacturer was used as fixed fortification level in the simulation (step 3).

The proportion of margarine consumers who will use the fortified alternative in the near future is unknown. It was assumed that the market share of the brand in question would be a good indicator, in this case estimated at 30\% (GfK Panel Service Benelux). Furthermore, the observed non-consumption on both reported days was assumed to be true non-consumption. Thirty per cent of the margarine consumers on the first observation day were randomly assigned to use folic-acid-fortified margarine. We assumed that all margarine consumers on day 1 had an equal chance to use the fortified margarine and were $100 \%$ brand loyal. Because it is unknown which $30 \%$ of the margarine consumers will use the fortified margarine, a random assignment was performed 100 times to get an insight on this uncertainty. For each of the 100 assignments, the habitual intake was estimated separately.

\section{Results of case study simulations}

Both the results of the simulation of mandatory and voluntary fortification are illustrated only for women aged 19-50 years $(N=1636$, pregnant and lactating women excluded).

\section{Mandatory fortification}

The habitual intake distribution of folate-equivalents after simulation of mandatory fortification of bread is pre- sented in Fig. 3. In comparison to the background diet (i.e. without fortification), the four fortification scenarios show a shift of the total distribution towards higher intake levels (Fig. 3). This can be explained by the fact that almost all subjects consumed bread. Besides, the intake distributions become wider after fortification. As expected, the higher the fortification level, the wider the distribution of intake levels. The confidence intervals around the curves express only the uncertainty of the estimation of the habitual intake of folate-equivalents using the ISU method, and not any other uncertainty due to, for example, errors in consumption or food composition data. The 95\% confidence intervals become wider with an increasing fortification level.

The results of the mandatory folic acid fortification of (butter)milk (Fig. 4) are similar to the results of the mandatory fortification of bread. Again, the distribution becomes wider after fortification. In contrast to the mandatory fortification of bread, the left tail of low folate-equivalent intake remains at an intake level similar

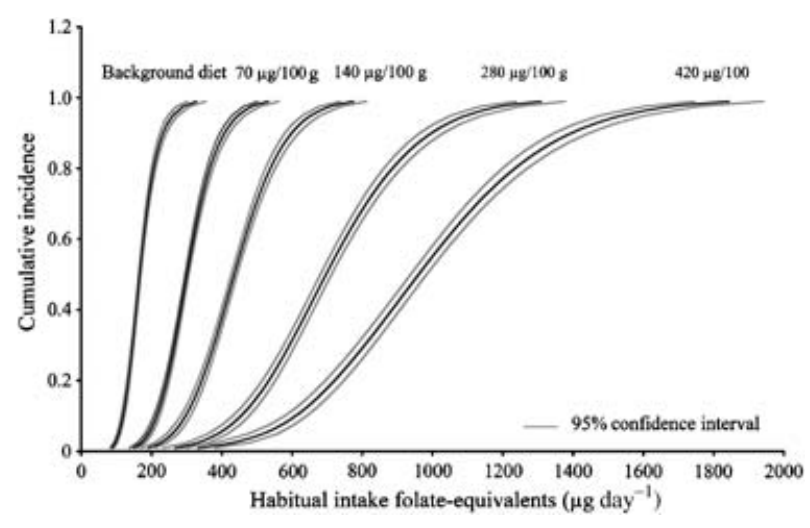

Fig. 3 Habitual intake of folate-equivalents without (background diet) and with mandatory fortification of bread with folic acid (four different levels) with 95\% confidence intervals of habitual intake for women aged $19-50$ years

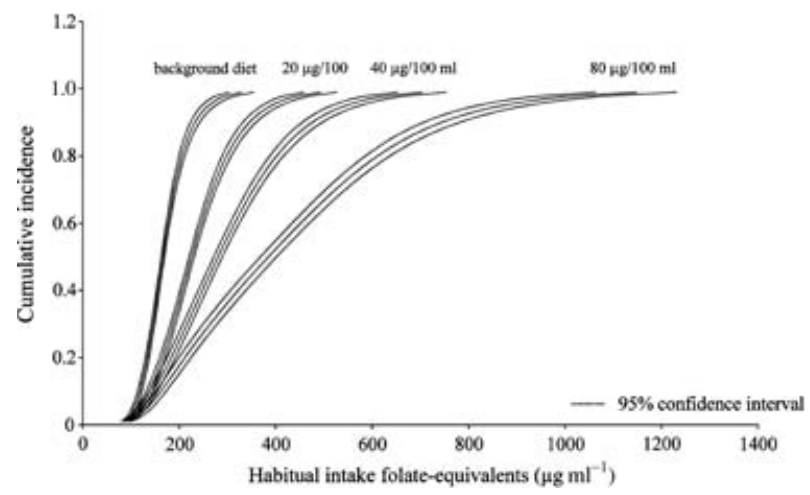

Fig. 4 Habitual intake of folate-equivalents without (background diet) and with mandatory fortification of (butter)milk with three different levels of folic acid, shown with $95 \%$ confidence intervals of habitual intake, for women aged 19-50 years 
to the background diet. This is due to the fact that there are more subjects not consuming (butter)milk compared to bread. For the highest fortification level (i.e. $160 \mu \mathrm{g}$ per $100 \mathrm{ml}$ ), the habitual folate-equivalent intake could not be estimated, probably because of problems with the transformation to a normal distribution. At a fortification level of $80 \mu \mathrm{g}$ per $100 \mathrm{ml}$, the intake distribution is not as fluent as the distributions for lower fortification levels. A plot of the probability density of the intake levels shows a distribution curve with two peaks (data not shown).

\section{Voluntary fortification}

The 100 simulated habitual folate-equivalent intake distributions after voluntary fortification of margarine are pictured in Fig. 5a. In comparison with the intake distribution of the background diet, the intake distributions after voluntary fortification are more positively skewed to the right. The left tails of the intake distribution of the background diet and the distribution after voluntary fortification are comparable, representing consumers that do not use fortified products. The folate-equivalent intake range in voluntary fortification becomes wider
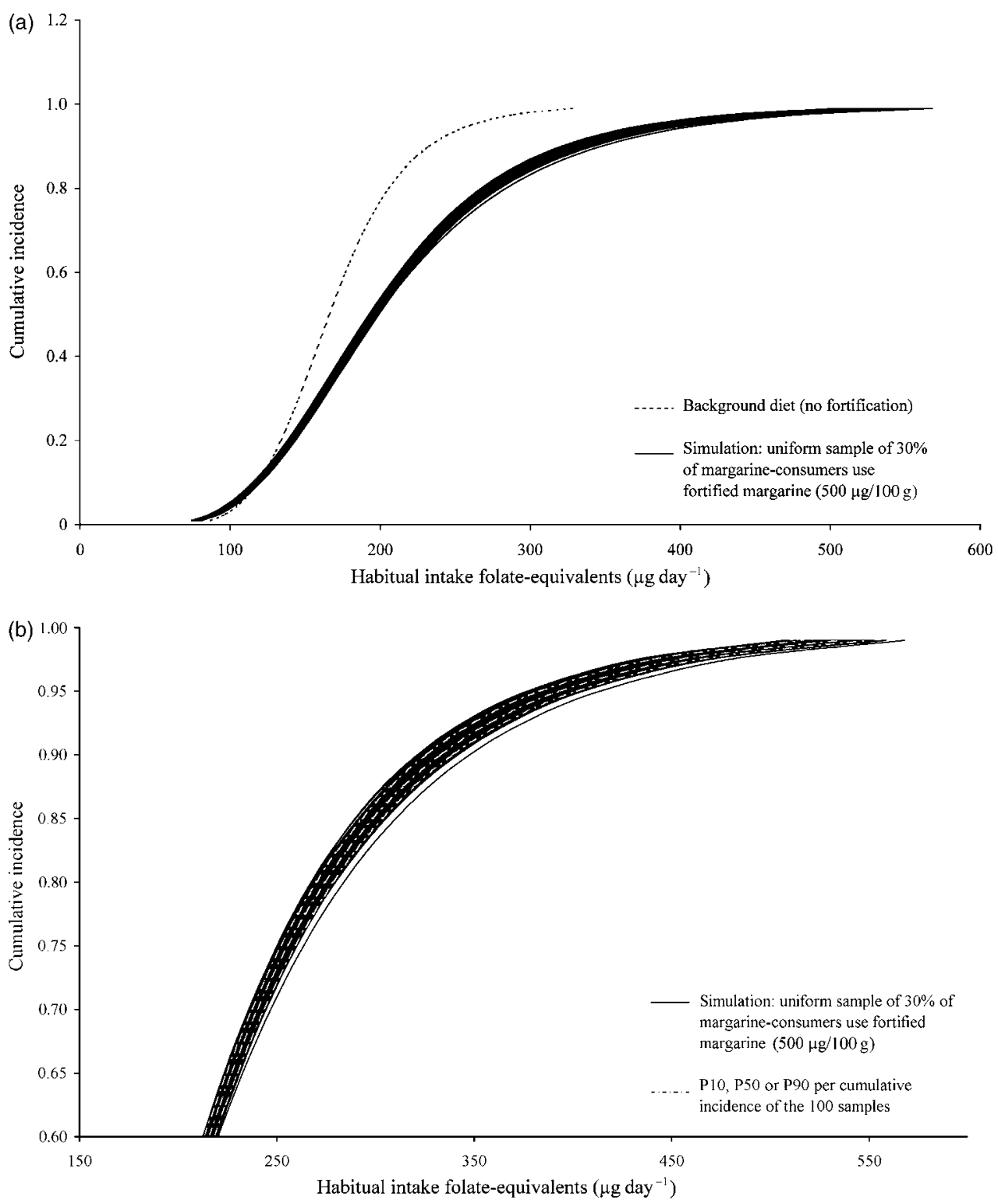

Fig. 5 (a) Habitual intake distribution of folate-equivalents of 100 random samples of which a uniform sample of $30 \%$ of the margarine-users consume fortified margarine (grey lines) and the habitual intake distribution of folate-equivalents from the background diet (i.e. no fortification) (black dotted line) for women 19-50 years (100\% brand-loyalty). Part of the graph that lies within the oval is pictured enlarged in Fig. 5 b. (b) Upper part of the habitual intake distribution of folate-equivalents of 100 random samples of which a uniform sample of $30 \%$ of the margarine-users consume fortified margarine (grey lines) for women aged 19-50 years; in white dotted lines P10, median and P90 are pictured to quantify the variation between the 100 samples 
compared to the background diet and mandatory scenarios.

The differences between the 100 curves reflect the uncertainty of the simulated intake, resulting from the uncertainty which $30 \%$ of the margarine consumers will use the fortified margarine. Figure $5 \mathrm{a}$ shows that the uncertainty is largest in the top part of the curve. This part is shown in more detail in Fig. 5b, giving the median, 10th and 90th percentiles of these 100 intake distributions.

\section{Discussion}

In this paper, a general framework for the simulation of the intake of functional ingredients from fortified foods but also from other sources (e.g. other foods and dietary supplements) is described.

\section{Framework}

The framework we presented is generally based on a combination of strategies used in already published case studies of simulated mandatory fortification ${ }^{2-10}$. The aim of these case studies was diverse, which likely resulted in the different methods applied. In addition, lack of data and differences in available data may also have had influence on the choice of the method used. In our framework, all steps needed in the simulation of fortification are described in general. Within this framework, it is possible to perform simulations using different types of data and data from various sources, and to give an insight on the resulting uncertainties. Furthermore, the calculation of habitual intake to estimate long-term exposure is a standard procedure in our framework. In addition to the simulation of mandatory fortification, the framework is also applicable for the simulation of voluntary fortification. To our knowledge, at this moment, no (case) studies on the simulation of voluntary fortification have been published.

As shown in our framework, the simulation of mandatory fortification is more straightforward than the simulation of voluntary fortification and requires fewer assumptions. For mandatory fortification, assumptions that are needed concern the type of carrier products, the level of fortification and - when food consumption is assessed with short-term methods - the observed nonconsumers vs. true non-consumers. Whereas for the simulation of voluntary fortification, additional assumptions regarding the market share of the fortified foods, the proportion of and the distribution within the population or subgroups of the population that will consume fortified foods (regular or incidental) are needed. These assumptions will result in uncertainty in the final estimated intake distributions. Moreover, uncertainties in the observed consumption data and available composition data will be of influence in all simulations ${ }^{19}$. We plea for an explicit description of the uncertainties, if possible by quantitative estimations of the effects of the uncertainty on the final outcome (for instance, as confidence intervals). When quantification of some uncertainties is not possible, which may often be the case, they should be described thoroughly.

In addition to scenarios mainly based on changes in food supply as described in our paper, scenarios based on changes in consumption patterns may also be expected due to, for instance, publicity campaigns. Our framework can easily be extended for this purpose by virtually changing the consumption data, for instance by increasing the number of subjects who will consume a specific food or changing the consumed amount.

\section{Habitual intake}

Effects of nutrition are often long term; therefore, habitual exposure is of a greater meaning than acute intake levels. However, long-term intake data are scarce. With foodfrequency questionnaires, habitual intake (often over a month or year) can be estimated immediately, though the questionnaires are often qualitative or semi-quantitative, and cover only part of the food supply (i.e. several hundred products). Food consumption surveys usually assess diet by short-term dietary assessment methods that cover only several observation days. With statistical procedures, observed intake can be corrected for withinperson variation to estimate habitual intake. Several statistical methods have already been developed to estimate the habitual intake of nutrients or food(group)s ${ }^{21-25}$. These statistical procedures cannot be applied to consumption data with only one observation day per subject. Some of the assumptions made in these statistical methods, like a smooth distribution and homogeneous within-person variation, may be violated due to simulated fortification practices ${ }^{43}$. This may result in data that cannot be transformed to a normal distribution (as is required in some methods) or problems with the estimation of the within-person variation. An adaptation of the current methods is needed to correct the data for within-person variation if the assumptions of current statistical methods are not met. Perhaps, correction for the within-person variation can be done for specific cluster groups which have homogeneous within-person variation (Carriquiry, 2006, personal communication).

\section{Case study}

We have illustrated the general framework with case studies for mandatory and voluntary folic acid fortification. At this moment, four case studies of mandatory folic acid fortification are published ${ }^{6,8-10}$. When these four case studies were compared with our framework, several differences in the simulation method were found. Only one study has estimated the total intake in folateequivalents, like in our study9. The other three studies have calculated the folic acid intake from fortified foods 
only ${ }^{8}$, summed the intake of folic acid from fortified foods and supplements, without taking into account differences in bioavailability ${ }^{6}$, or added up intake of dietary folate and folic acid from different sources without correcting for the difference in bioavailability ${ }^{10}$. Two studies took into account the intake from dietary supplements ${ }^{6}$. Several of the above-described problems with the calculation of the habitual intake were also faced in these case studies.

The assumption that observed non-consumers on the study days are habitual non-consumers will often be incorrect. It is therefore better to estimate the probability of consuming a certain amount on each day. Additional data about the propensity of consumption during a longer timeframe are of use to make valid estimations ${ }^{44}$. In the voluntary approach, 30\% of the (low-fat) margarine users were uniformily sampled to be a consumer of fortified (low-fat) margarine. It is unlikely that the chance that somebody will be a consumer of fortified products is equal for the whole population ${ }^{45}$. An insight on determinants of food consumption may assist in taking valid conditional samples out of the population.

\section{Conclusion}

The general framework we presented for the simulation of the intake of functional ingredients from different sources can be applied for a range of aims. Important uses of our framework are getting an insight on changing intake distributions due to changes in, for instance, policies or consumption, finding out the optimal fortification scenario to create an intake of the population between recommendations and the UL, or risk-benefit analyses. A novelty of this framework is that it can be used to estimate intakes not only from mandatory fortification but also from voluntary fortification, as was illustrated by the case study.

The framework describes the different steps required for the simulation of intake and the required data. Even with incomplete data, or data from different sources, the (habitual) intake distributions can be estimated using assumptions, statistical procedures or probabilistic modelling approaches. The relevant outcome measure is, in most instances, the population distribution of habitual total intake. It is important that the whole procedure of simulation of fortification is described well, so that an insight can be given on the uncertainties and knowledge gaps to be filled in future. Besides, using and describing the same general framework as a basis will help to make outcomes from different studies (and countries) better comparable.

\section{Acknowledgements}

Sources of funding: National Institute for Public Health and the Environment, The Netherlands.
Conflict of interest declaration: The authors declare that there are no conflicts of interest.

Authorship responsibilities: All authors contributed to the design of the framework, interpreting the data and writing the manuscript. J.K. performed the simulations of the case study.

Acknowledgements: We thank A Carriquiry and G Camaño-Garcia of the Department of Statistics, Iowa State University, USA for statistical support and invaluable assistance with the SIDE software; D ter Doest (TNO Quality for Life Institute, Zeist, The Netherlands) for practical assistance with the SIDE software; and ALM Dekkers (RIVM) for statistical assistance.

\section{References}

1 Park YM, McDowell MA, Hanson EA, Yetley EA. History of cereal-grain product fortification in the United States. Nutrition Today 2001; 36: 124-37.

2 Kuhlmann K, Lindtner O, Bauch A, Ritter G, Woerner B, Niemann B. Simulation of prospective phytosterol intake in Germany by novel functional foods. British Journal of Nutrition 2005; 93: 377-85.

3 Raulio S, Nurttila A, Mannonen L. Adding Phytosterols and Stanols to Food - Modelling the Amount Received by Finnish Adults. Publication No. 10/2001. Helsinki: National Food Agency, 2001.

4 Brussaard JH, Hulshof KF, Lowik MR. Calculated iodine intake before and after simulated iodization (Dutch Nutrition Surveillance System). Annals of Nutrition $\mathcal{E}$ Metabolism 1995; 39: 85-94.

5 Suojanen A, Raulio S, Ovaskainen ML. Liberal fortification of foods: the risks. A study relating to Finland. Journal of Epidemiology and Community Health 2002; 56: 259-64.

6 Green T, Newton R, Bourn D. Estimated folic acid intakes from simulated fortification of the New Zealand food supply. New Zealand Medical Journal 2003; 116: U294.

7 Johnson-Down L, L'Abbe MR, Lee NS, Gray-Donald K. Appropriate calcium fortification of the food supply presents a challenge. Journal of Nutrition 2003; 133: 2232-8.

8 Bausch-Goldbohm RA, Hulshof KFAM, Brants HAM, Van den Berg H, Bouman M. De inneming van foliumzuur door verschillende bevolkingsgroepen in Nederland voor en na verrijking van bepaalde voedingsmiddelen. Voedselconsumptiepeiling 1992. Publication No. V 95.184. Zeist: TNO, 1995 [in Dutch].

9 Burger M, Weissenborn A, Klemm C, Przyrembel H, Mensink G. Möglichkeiten zur Verbesserung der Folatversorgung. Eine Mehlanreicherung auch für Deutschland? Ernäbrungs-Umschau 2004; 51: 318-24 [in German].

10 Firth Y, Murtaugh MA, Tangney CC. Estimation of individual intakes of folate in women of childbearing age with and without simulation of folic acid fortification. Journal of the American Dietetic Association 1998; 98: 985-8.

11 Ocké MC, Buurma-Rethans EJM, Fransen HP. Dietary supplement use in the Netherlands. Current data and recommendations for future assessment. Report No. 350100001/2005. Bilthoven: RIVM, 2005.

12 Millen AE, Dodd KW, Subar AF. Use of vitamin, mineral, nonvitamin, and nonmineral supplements in the United States: The 1987, 1992, and 2000 National Health Interview Survey results. Journal of the American Dietetic Association 2004; 104: 942-50.

13 De Jong RJ, Verwei M, West CE, van Vliet T, Siebelink E, van den Berg $\mathrm{H}$, et al. Bioavailability of folic acid from fortified 
pasteurised and UHT-treated milk in humans. European Journal of Clinical Nutrition 2005; 59: 906-13.

14 De Jong N, Pijpers L, Bleeker JK, Ocke MC. Potential intake of phytosterols/stanols: results of a simulation study. European Journal of Clinical Nutrition 2004; 58: 907-19.

15 Flynn A, Moreiras O, Stehle P, Fletcher RJ, Muller DJ, Rolland V. Vitamins and minerals: a model for safe addition to foods. European Journal of Nutrition 2003; 42: 118-30.

16 Rasmussen SE, Andersen NL, Dragsted LO, Larsen JC. A safe strategy for addition of vitamins and minerals to foods. European Journal of Nutrition 2005; 45: 123-35.

17 Stichting NEVO/NEVO Foundation. NEVO table 2001, Dutch Food Composition Database. The Hague: Netherlands Bureau for Nutrition Education, 2001.

18 Deharveng G, Charrondiere UR, Slimani N, Southgate DA, Riboli E. Comparison of nutrients in the food composition tables available in the nine European countries participating in EPIC. European Prospective Investigation into Cancer and Nutrition. European Journal of Clinical Nutrition 1999; 53: $60-79$.

19 World Health Organization (WHO). A Model for Establishing Upper Levels of Intake for Nutrients and Related Substances. Report of a Joint FAO/WHO Technical Workshop on Nutrient Risk Assessment, Geneva, 2-6 May 2005. Geneva: WHO/FAO, 2006.

20 Gibson RS. Principles of Nutritional Assessment. New York: Oxford University Press, 2005.

21 Hoffmann K, Boeing H, Dufour A, Volatier JL, Telman J, Virtanen M, et al. Estimating the distribution of usual dietary intake by short-term measurements. European Journal of Clinical Nutrition 2002; 56(Suppl. 2): S53-62.

22 Nusser S, Carriquiry A, Dodd K, Fuller W. A semiparametric transformation approach to estimating usual daily intake distributions. Journal of the American Statistical Association 1996; 91: 1440-9.

23 Slob W. Modeling long-term exposure of the whole population to chemicals in food. Risk Analysis 1993; 13: 525-30.

24 Slob W. Probabilistic dietary exposure assessment taking into account variability in both amount and frequency of consumption. Food and Chemical Toxicology 2006; 44: 933-51.

25 National Research Council. Nutrient Adequacy. Assessment Using Food Consumption Surveys. Washington, DC: National Research Council, 1986.

26 Basiotis PP, Welsh SO, Cronin FJ, Kelsay JL, Mertz W. Number of days of food intake records required to estimate individual and group nutrient intakes with defined confidence. Journal of Nutrition 1987; 117: 1638-41.

27 Carriquiry AL. Estimation of usual intake distributions of nutrients and foods. Journal of Nutrition 2003; 133: 601S-8S.

28 Ocké MC, Hulshof KFAM, Bakker MI, Stafleu A, Streppel MT. Naar een nieuw Nederlands voedingspeilingsysteem. Report No. 350050001/2005. Bilthoven: RIVM/TNO, 2005 [in Dutch].

29 Lewis CJ, Crane NT, Wilson DB, Yetley EA. Estimated folate intakes: data updated to reflect food fortification, increased bioavailability, and dietary supplement use. American Journal of Clinical Nutrition 1999; 70: 198-207.

30 Gibney MJ, McCarthy SN. Approaches to assessment of exposure to food- and supplement-derived amino acids. Journal of Nutrition 2004; 134: 1660S-3S; discussion 1664S-6S, 1667S-72S.

31 Gibney MJ, van der Voet $\mathrm{H}$. Introduction to the Monte Carlo project and the approach to the validation of probabilistic models of dietary exposure to selected food chemicals. Food Additives and Contaminants 2003; 20: S1-7.

32 Vose D. Risk Analysis. A Quantitative Guide. Chichester: John Wiley \& Sons, 2000.

33 Zo eet Nederland 1998. Resultaten van de Voedselconsumptiepeiling 1998. The Hague: The Netherlands Nutrition Centre, 1998 [in Dutch].

34 Jansen M, Hulshof K, Konings E, Brussaard T. Foliumzuur in Nederland: wat is de gebruikelijke inneming? Voeding $\mathrm{Nu}$ 2002; 4: 25-9 [in Dutch].

35 Health Council of the Netherlands. Voedingsnormen: vitamine $B_{6}$, foliumzuur en vitamine $B_{12}$. Publication No. 2003/04. The Hague: Health Council of the Netherlands, 2003 [in Dutch].

36 Bailey LB. Dietary reference intakes for folate: the debut of dietary folate equivalents. Nutrition Reviews 1998; 56: 294-9.

37 Suitor CW, Bailey LB. Dietary folate equivalents: interpretation and application. Journal of the American Dietetic Association 2000; 100: 88-94.

38 Iowa State University. A User's Guide to C-SIDE. Technical Report 96-TR 31. Ames, IA: Department of Statistics and Center for Agricultural and Rural Development, Iowa State University, 1996.

39 Regulations amending the Food and Drug Regulations (1066). Canada Gazette Part II 1998; 132: 3025-33.

40 Food and Drug Administration. Food standards: amendment of standards of identity for enriched grain products to require addition of folic acid. Final rule. Federal Register 1996; 61: 8781-807.

41 Hertrampf E, Cortes F, Erickson JD, Cayazzo M, Freire W, Bailey LB, et al. Consumption of folic acid-fortified bread improves folate status in women of reproductive age in Chile. Journal of Nutrition 2003; 133: 3166-9.

42 Verwei M. Bioavailability of folate from fortified milk products. Dissertation, Wageningen University, Wageningen, 2004.

43 Dodd KW. A Technical Guide to C-SIDE. Software for Intake Distribution Estimation. Technical Report 96-TR 32. Ames, IA: Iowa State University, 1996.

44 Tooze JA, Midthune D, Dodd KW, Freedman LS, KrebsSmith SM, Subar AF, et al. A new statistical method for estimating the usual intake of episodically consumed foods with application to their distribution. Journal of the American Dietetic Association 2006; 106: 1575-87.

45 De Jong N, Ocke MC, Branderhorst HA, Friele R. Demographic and lifestyle characteristics of functional food consumers and dietary supplement users. British Journal of Nutrition 2003; 89: 273-81. 